\title{
Adoption and use of an injury prevention exercise program in female football: A qualitative study among coaches
}

Hanna Lindblom, Siw Carlfjord and Martin Hägglund

The self-archived postprint version of this journal article is available at Linköping University Institutional Repository (DiVA):

http:// urn.kb.se/ resolve?urn=urn:nbn:se:liu:diva- 147150

N.B.: When citing this work, cite the original publication.

Lindblom, H., Carlfjord, S., Hägglund, M., (2018), Adoption and use of an injury prevention exercise program in female football: A qualitative study among coaches, Scandinavian J ournal of Medicine and Science in Sports, 28(3), 1295-1303. https:/ / doi.org/ 10.1111/ sms. 13012

Original publication available at:

https:/ / doi.org/ 10.1111/ sms. 13012

Copyright: Wiley (12 months)

http:/ / eu.wiley.com/WileyCDA/ 


\title{
Adoption and use of an injury prevention exercise programme in female football: a qualitative study among coaches
}

Running head: Injury prevention programme adoption and use

\author{
H. Lindblom ${ }^{1}$, S. Carlfjord ${ }^{2}$, M. Hägglund ${ }^{1}$
}

${ }^{1}$ Division of Physiotherapy, Department of Medical and Health Sciences, Linköping

University, Linköping, Sweden

${ }^{2}$ Division of Community Medicine, Department of Medical and Health Sciences, Linköping University, Linköping, Sweden

Corresponding author. Hanna Lindblom, Division of Physiotherapy, Department of Medical and Health Sciences, Linköping University, Linköping, Sweden. Tel.: +46 132847 13. Email: hanna.lindblom@liu.se 
This study focuses on an injury prevention exercise programme (IPEP), Knee Control, which has been shown to reduce the incidence of acute knee injury in female adolescent football players. The aim was to explore the factors influencing coaches' adoption and use of Knee Control within female football in Sweden. This was a qualitative study involving interviews with 20 strategically selected coaches for female football teams, predominantly adolescent teams. The semi-structured interview guide was influenced by the Health Belief Model, and an ecological perspective was adopted during the interviews. Interviews were analysed with qualitative content analysis. The results illustrate the different influences that interact on adoption and use of Knee Control by coaches. The coaches described themselves as crucial for Knee Control adoption and use, but external facilitators and barriers such as resources for training, social support from other coaches, clubs and football associations and player buy-in were also described as important. Knee Control characteristics, such as how well the programme fit the team, also influenced use of Knee Control. Many coaches modified the programme to improve player buy-in and Knee Control fit. Such modifications may risk compromising the preventive effect but may increase feasibility, i.e. the ease of using Knee Control, and thereby long-term use. These findings may guide the design and delivery of future IPEPs, and improve use of Knee Control, for example by expanding the programme to fit different target groups and supporting coaches and players in the use of Knee Control. Key words: Neuromuscular training, dissemination, implementation, youth, team sports 


\section{Introduction}

Sports participation is associated with a risk of injury that may affect quality of life and function negatively for several years ${ }^{1}$. Hence, a number of different injury prevention exercise programmes (IPEPs) have been developed to prevent sports injuries, especially among youths participating in team sports. Some of these IPEPs have been shown to be efficacious in reducing the incidence of injury ${ }^{2-5}$. To prevent injuries in the long term, the IPEPs must be adopted and maintained by the users, which is a challenge ${ }^{6}$. Usually the team coaches are the key to adoption and use of IPEPs at amateur and youth level ${ }^{7-8}$. Although coaches express intention to use IPEPs and have positive attitudes towards them, and clubs accept a policy regarding IPEP use, the adoption of IPEPs has been limited ${ }^{9-10}$.

IPEP training at a sufficient dose is key for maximum preventive effect, but ensuring IPEP adherence over time is a challenge ${ }^{11-13}$. Coaches' knowledge and beliefs about injuries do not seem to translate into adherence to using IPEPs ${ }^{14}$, and it may be difficult for coaches to follow the IPEP recommendations on training dosage ${ }^{15}$. Programme fidelity (using the IPEP as intended in terms of dosage, exercise selection, set-up) may also affect the preventive effect, but studies have shown that coaches often modify the programmes ${ }^{10,16-18}$.

Research on implementation of IPEPs may be guided by behavioural and social science theories and models because a behavioural change is usually necessary when implementing an IPEP. The Health Belief Model (HBM) ${ }^{19}$ has been applied in some studies within male Australian football and youth male football to learn about perceptions of injury risks and value of IPEPs ${ }^{7,20-21}$, facilitators and barriers for adoption ${ }^{20}$ or maintenance ${ }^{21}$ of IPEPs and how the programmes can be improved ${ }^{7}$. In these studies the $\mathrm{HBM}^{7}$ or the HBM together with the RE-AIM model ${ }^{20-21}$ (Reach, Effectiveness, Adoption, Implementation and Maintenance) informed development of the questionnaires. According to the HBM, people 
weigh up the perceived susceptibility and severity of injuries/illnesses against the benefits and barriers of doing a preventive action, such as using an IPEP. Some triggering events (cues to action) and self-efficacy may also influence the preventive action ${ }^{22}$. Based on an ecological perspective ${ }^{23}$, personal, interpersonal and organizational factors as well as factors related to the surrounding community and society may affect whether a coach chooses to adopt IPEPs ${ }^{24}$. In general, knowledge about the vital factors for effective implementation of IPEPs in team sports is lacking ${ }^{8}$. It is also relatively unknown how the coaches can be supported in the implementation ${ }^{9,25}$.

This study focuses on Knee Control (Knäkontroll, SISU Idrottsböcker, Sverige 2005), a coach-led IPEP shown to reduce the rate of anterior cruciate ligament injury with $64 \%$ in female adolescent football players ${ }^{4}$, with even better effect (88\%) among players who used Knee Control at least once a week ${ }^{11}$. Knee Control contains six principal exercises at four levels of difficulty and six additional pair exercises. The programme takes 10-15 minutes to complete and is to be used in the warm-up before training. Knee Control is available commercially on a CD-ROM/DVD and as a leaflet. In addition, it is available as a freely downloadable mobile application (app). In a previous study, we found that, although many coaches knew about and had adopted Knee Control, the majority had modified the content and/or training dose and did not use all six exercises on every session and/or did not do the training as often as prescribed ${ }^{17}$. However, the reasons for these modifications are not known, and we need to know more about how to support coaches when adopting and using the programme. The aim of the present study was to explore the factors influencing coaches' adoption and use of Knee Control within female football in Sweden. 


\section{Materials and methods}

This was a qualitative study involving interviews with coaches for female football teams in Sweden. Data collection started in late 2014 and ended late spring 2015. Interviews were analysed using qualitative content analysis ${ }^{26}$.

\section{Participants}

For the present study we invited coaches from eight of Sweden's 24 football districts. In these districts Knee Control was evaluated regarding preventive efficacy in $2009^{4}$ before national dissemination of the programme started. Some of the coaches belonged to clubs that had taken part in the earlier study, but none of them had participated in the study themselves. The aim was to include individuals with knowledge of but varying amounts of experience of using Knee Control through maximum variation sampling ${ }^{27}$. This was accomplished by inviting coaches for players aged from 10 years to senior level, in different sized clubs, in both rural and urban areas. Coaches were strategically selected to obtain maximum variation. Most participating coaches were the teams’ main coach. Most teams did not have any medical staff or athletic trainers. Coaches were contacted consecutively by e-mail and invited to take part in the study until 20 coaches were included. Coaches who did not respond to the e-mail received one reminder. Since coaches were contacted consecutively, when someone declined participation or did not respond, another coach with similar characteristics was chosen, to ascertain maximum variation according to the aforementioned criteria. To reach the intended sample, 50 coaches were contacted; 6 declined participation and 24 did not respond. All coaches received detailed information about the study.

The mean age of the participating coaches was 44 years (range, 23-52 years), 16 were the parent of (at least) one of the players in the team, and five were female. The coaches had been actively coaching female adult or youth football teams for 1-15 years (average, 7 years). 
Most coached youth teams with players aged 10-17 years; three coached senior teams. Most had taken part in the first basic courses for coaches; some who were coaching more as a profession had taken several coaching courses. Most of the coaches learnt about Knee Control through the instructive material (app, CD-ROM, leaflet); a few coaches had also taken part in practical workshops. Nine of the coaches had used Knee Control for a short time (less than 1.5 years) and 11 for a longer time (2-8 years). One of the coaches had just started and four had stopped using it after $0.5-5$ years of usage. Those who did not use it any longer either recommended players to do the training on their own, only used the programme during pre-season and had not started yet after the competitive season, or did not use it any longer since they were currently coaching a senior team.

Written informed consent was obtained from all coaches. The study was approved by the Regional Ethical Review Board in Linköping (Dnr 2014/327-31).

\section{Interview guide}

A semi-structured interview guide (see Supporting Information) containing five openended questions covering the coaches' thoughts and experiences of Knee Control, their experiences of injuries, their role as a coach and how they used Knee Control and their reasons for use or non-use, was applied. Probes were used when necessary. Probes regarding reasons for adoption in terms of health behaviour were influenced by the HBM constructs of perceived susceptibility, severity, benefits and barriers and additionally cues to action and self-efficacy. An ecological perspective was also applied, considering that the coach is part of a system, not an isolated unit. The ecological perspective was embraced when probing for more thorough answers for example by asking whether the coaches were influenced by anything else, hence both models were used in parallel. A short custom made questionnaire 
covered background information about coaching experience and coach education, whether the team used Knee Control at present and coach and player age.

In addition to the 20 interviews, two pilot interviews were carried out with two other coaches for female youth football players to test the interview guide and the analysis procedure. No major changes were made to the interview guide after the pilot interviews.

\section{Data collection}

The interviews were audio recorded and transcribed verbatim. The coaches could opt for interview mode (face-to-face or telephone interview) and, hence, one interview was done face-to-face, and 19 over the phone.

The interviews were performed by the first author (HL), a female physiotherapist and PhD student with experience of previous studies on Knee Control and conducting and analysing qualitative interviews. None of the coaches had any relation to HL beforehand. The interviews lasted 39 minutes on average (range, 23-56 minutes).

\section{Data analysis}

The interviews were analysed using qualitative content analysis, and as little was known beforehand about the subject, conventional content analysis was chosen ${ }^{28}$. Even though the interview guide was theoretically driven by its influences from the HBM and the ecological model the analysis was inductive without pre-defined categories and with focus on responding to the study aim. The theoretical models were applied again first in the discussion of the study findings. The pilot interviews were analysed by all three authors and as the results did not differ substantially, HL continued to perform an initial analysis of each interview, which was later discussed with $\mathrm{SC}$ and $\mathrm{MH}$, who are experienced in qualitative 
methodology and implementation research (SC), and sports science and injury prevention research $(\mathrm{MH})$. The pilot interviews were not included in the main analysis.

The transcripts were read repeatedly to obtain an overall picture of the content. Meaning units, extracted parts of the text responding to the study aim, were marked in the text, condensed and coded. Preliminary codes were created using words and phrases that the coaches themselves used. Some of these codes were later re-worded to better cover the content of the condensed meaning units. Codes with related content were grouped together in sub-categories and categories intended to be as internally homogeneous and externally heterogeneous as possible. Interpretations were continuously checked against the whole interview, aiming for truthfulness. An iterative process was applied, moving back and forth between interviews and analysis and forming new categories until a pattern emerged and thereafter using these categories for the further analysis and adding new categories if necessary. Finally, a negative case analysis was carried out; information within each category was examined to make sure all codes had been correctly categorized.

\section{Results}

One overall theme based on the latent, underlying, content, three categories and eight sub-categories emerged from the analysis. The theme Interacting influences on coach adoption and use of Knee Control illustrates a close connection between the three categories: Coach motivation for adoption and use of Knee Control, External facilitators and barriers, and Knee Control characteristics. The individual coach and his or her motivation was crucial for Knee Control adoption and use, but it was also influenced by external facilitators and barriers, and by the characteristics of Knee Control. Quotations illustrating the sub-categories are presented in Tables $1-3$. 


\section{Coach motivation for adoption and use of Knee Control}

This category describes the coaches’ motivation for Knee Control adoption and use based on their views on injuries and the reasons for injuries in football, whether and how they believed injuries may be prevented, and what injuries they believed Knee Control could prevent. Without buy-in from the coach, no regular use of Knee Control would take place (Table 1).

\section{Views on injuries in football}

The coaches saw football as an injury prone sport, especially for girls and regarding knee injuries. Most coaches had experience of acute and/or overuse injuries to themselves, family members or players in their club. They believed multiple factors contributed to injury occurrence: unequal players playing against each other (e.g. different ages or sizes), poorly trained players, risk-taking personality, returning to sport too soon after injury, tough training schedule, poor ability to read the game or uneven surface. Some coaches, however, thought the reason for injuries was unclear and that injuries occur by chance. Some expressed that they knew too little about injuries.

Injury prevention attitude

Predominantly, coaches who had taken part in several coaching courses described different methods to prevent injuries such as focusing on the whole player, making sure all players are well trained, delivering preventive training continuously, avoiding risk moments and warming up properly. Most coaches were driven by their own convictions about the importance of injury prevention and their own experiences of injuries and their consequences. No one expressed that they felt compelled to use Knee Control. Some felt it was obvious to use an evidence-based IPEP. Some found injury prevention a necessity for further football playing and suggested it should be mandatory in girls' teams. However, some parental coaches lacked conviction that injury prevention was important and predominantly saw 
football as a way to offer the girls a meaningful spare-time activity. Some coaches stated it was a matter of prioritization and although they prioritized prevention, their colleagues might prioritize other things.

Beliefs about the effects of Knee Control

The coaches believed Knee Control had several effects if used regularly and with continuity, such as improving performance, stability and strength, but first and foremost reducing the incidence of acute and overuse injury. Some coaches, however, thought the effect of Knee Control was too small to make preventive training a priority. One challenge with prevention mentioned by the coaches was the difficulty seeing the direct effects and the long-term use needed for effect.

\section{External facilitators and barriers for adoption and use of Knee Control}

This category describes how the coaches' adoption and use of Knee Control was influenced by external facilitators and barriers, such as having support from other coaches, the club and district football association (FA), the availability of resources for Knee Control use and the players. It also illustrates how coaches who believed in the effects of Knee Control did their best to work around these barriers (Table 2).

Social support when adopting and using Knee Control

Peer exchange between coaches was an efficient way of spreading information about Knee Control and how some coaches first came into contact with it. A few coaches learnt about Knee Control via their club and district FA or during general coaching education. Because new coaches come and go all the time, some coaches stressed that information about Knee Control has to be spread continuously. When the coaches saw or heard about others using Knee Control, they believed that they had made the right decision to adopt Knee 
Control. Some district FAs and clubs were dedicated to preventive training, but generally few coaches felt supported by the club or district FAs.

The preventive training was often led by one of the coaches and the other team coaches prepared the forthcoming drills. In some cases, all coaches were engaged elsewhere and instructed some players to lead the training. The training was usually only carried out when the designated coach was present or had left clear instructions for the other coaches. However, in a few teams, all coaches were committed to preventive training. Many coaches, predominantly parental coaches, asked for more support and feedback when using the exercises, for example from an expert visiting the team. The coaches also thought practical education could teach them more about the execution of the exercises, even though some had initially taken part in workshops.

\section{Resources for use of Knee Control}

Resources in terms of financial resources, time, access to indoor and outdoor venues, access to Knee Control material and coach availability influenced the use of Knee Control. Having had education in Knee Control or not and the amount of general coaching courses also influenced how Knee Control was used; coaches who had not taken part in workshops or education were more uncertain about the execution of the exercises. Many coaches used the app when choosing exercises and as a basis for the execution of the exercises. They found the app easy to use and appreciated the filmed exercises. However, some coaches used only the leaflet describing the exercises.

One challenge was that most teams were dependent on parental coaches and nonprofit commitment, which limited the time and possibility for using Knee Control. One solution was to designate one coach with responsibility for Knee Control use, relieving the head coach of this duty. This was already the case in some senior and elite teams. In a few 
clubs, the teams cooperated and had their junior and senior teams do the preventive exercises together, which was also suggested by many coaches. However, in most cases the teams were isolated units.

Player-related factors influencing the use of Knee Control

Coaches also believed that their use of Knee Control was influenced by the players. Most coaches had been coaching their team for several years and noticed that the execution of the exercises and the players' attitude towards the training changed over time. During the first years, the players found some of the exercises difficult but were more curious and positive towards the training compared with later on. Over time, some coaches planned to let the players take over responsibility for Knee Control training, either by doing the exercises together with the team without being led by the coach or individually at home. However, others emphasized that the training needs to take place within the team and be led by a coach. Many coaches believed that there was a need to improve player movement quality and motivation when using Knee Control. To increase player motivation, coaches suggested use of role models, involving the players more during training and making the training more fun. They also expressed a wish for greater awareness about injuries and the benefits of prevention among players. They suggested this could be obtained by education and information via the district FA and also via media coverage, making the issue more known to everyone.

\section{Programme characteristics influencing adoption and use of Knee Control}

This category describes how the coaches perceived that the exercises and the programme as a whole fit the team and the feasibility of Knee Control, i.e. how programme characteristics influenced adoption and use of Knee Control by coaches (Table 3). 
Knee Control fit

The coaches found Knee Control easy and safe to use, even if they had not heard about Knee Control before starting to use it. The fact that Knee Control was perceived to contain simple exercises that the coaches recognized and understood facilitated its use. The coaches also appreciated that no equipment was needed. Some found the exercises too easy, some too difficult and others as just right, predominantly dependent on player age. Some believed it was necessary to tailor exercises over time to fit player maturity. In addition to preventing injuries, coaches thought the training must be fun because the players, after all, are there to play football. The coaches appreciated the pair exercises because they believed these increased player motivation. To make Knee Control fit the team even better and gain more positive experiences for the players, they wished for more examples of progression and modifications. To improve the chances of getting the training done and increasing player buyin, coaches also pondered over the best training set-up. Many had already modified Knee Control, for example by adding other exercises, variants of the existing exercises (also with equipment) and competitive elements, selecting a few exercises per session or doing exercises in between other drills. Weather and climate conditions was also a reason for modifying Knee Control.

Knee Control feasibility

The way coaches used Knee Control varied over time and season, and among coaches, but the training dose was usually lower than that recommended. Some did almost the same exercises every time, whereas others varied the exercises. Some used all six exercises every session, others used a few exercises per session. Coaches for elite or senior players sometimes used periodization with different focuses during the season; with weights, focusing on explosive muscle action or slow and controlled movements. To attain good continuity, several coaches recommended establishing a routine to make preventive training 
as natural as warming up has now become. As routines changed, such as during seasonal breaks, preventive training often ceased. Most coaches believed correct execution of the exercises was important for maximising the effect, and hence, most coaches instructed, gave feedback and corrected the players during Knee Control training. However, some coaches were unsure whether their players performed the exercises correctly.

\section{Discussion}

\section{Complex interacting influences on coach adoption and use of Knee Control}

We found that the coaches experienced that adoption and use of Knee Control were dependent on their motivation, external facilitators and barriers such as the availability of social support, resources and players buy-in, and Knee Control characteristics. However, most important were the coaches themselves, because adoption would usually not take place without a motivated coach. The external facilitators and barriers and the characteristics of Knee Control influenced continued use.

When considering the results in light of the HBM, coach motivation corresponds well with the perceived susceptibility, severity of injuries and benefits of using Knee Control described in the model. The HBM concept of perceived barriers was illustrated by the second category describing the external barriers for Knee Control use. The HBM concepts of cues to action and coaches' self-efficacy were, however, only covered in parts. Influences from other coaches using or talking about the programme was one cue-to-action mentioned by some coaches. Self-efficacy was partly covered from the coach perspective when a few coaches expressed their uncertainty about the execution of the exercises and wished for more on-field support. This is in line with a questionnaire study in female football showing low selfefficacy among coaches when instructing players, using the programme with the team and 
continuing to do so for an entire season ${ }^{29}$. In the same study player self-efficacy in completing the exercises was also rather low ${ }^{29}$. This was not measured in the present study but some coaches suggested letting players lead the training and using role models to increase their motivation, which may also improve their self-efficacy in using the programme. This may be one external facilitator for Knee Control use.

The two latter categories, external facilitators and barriers and Knee Control characteristics, were predominantly illustrated by the ecological perspective. This perspective was valuable because the coaches described many external influences on their adoption and use of Knee Control. What was surprising was the close and complex relationship among the three categories, which was also illustrated in the theme, thus making it difficult to distinguish the categories in the analysis. Hence, when developing strategies to improve Knee Control adoption and use, focus may be on either one or all three factors. The results of the present study are in line with a complex approach ${ }^{30}$ where interactions and interrelations among factors that may influence preventive outcomes are taken into account. Some facilitators for programme use, such as access to programme materials, having proper equipment and enough space for the training, and some barriers, such as lack of time, tough competition schedule, poor player buy-in and lack of coach resources, have been reported in other populations with other IPEPs ${ }^{15-16,29}$. The coaches' statements in the present study confirm these results, but also stress the importance of social support and prioritization of IPEP use in addition to a user-friendly IPEP. To the authors' knowledge, this is the first indepth qualitative interview study with coaches covering factors influencing adoption and use of an IPEP. 


\section{Coach support}

Even though the decision to start using Knee Control was made by the coaches, some coaches wished for joint support for Knee Control use from the FAs, clubs and other coaches, to highlight that prevention was a priority. When the efficacy of Knee Control was originally studied $^{4}$, a formal dissemination process led by the Swedish FA with practical workshops was launched, but this has ceased over the years. Hence, formal dissemination of Knee Control could probably be improved, especially because relying on passive mechanisms for spreading IPEPs tends to be unsuccessful ${ }^{10}$. Including the IPEP in general coach education has also been suggested to improve the spread of IPEPs ${ }^{31}$; this has been done in Sweden recently (spring of 2016). By including the IPEP in coach education and increasing awareness continuous use of the IPEP in the clubs may be facilitated, which is important because coaches come and go over time. Focusing on the supportive functions instead of solely on the coach is in line with findings in male youth professional football ${ }^{18,21}$. Additionally, a questionnaire study in youth female football showed that the odds of using a preventive programme increased when the main coach was supported by strength and conditioning personnel or support personnel ${ }^{32}$. Further education was also asked for by those who had already implemented the programme ${ }^{32}$, which is also in line with the present findings. However, offering more support and workshops requires resources both in terms of financial support and a responsible organization to handle these issues, which is a challenge within the non-profit organization of Swedish youth football.

\section{Player buy-in and tailoring}

It is important to get the players on board because they are the end-beneficiaries of the training. In line with earlier studies ${ }^{21,29}$, poor player buy-in of Knee Control was mentioned as a potential barrier for its use in the present study. Earlier studies have shown that modifications of IPEPs occur ${ }^{16-18,32}$ and what this study adds is increased understanding 
about some of the reasons for these modifications. Our coaches had done their best to overcome barriers for Knee Control adoption and use, for example by modifying Knee Control to fit their team and increase player buy-in despite limited resources and lack of support. Although modifications of IPEPs have often been regarded as negative, this study highlights the benefits of the modifications. Modifying programme content to make it fit the team better may improve the chances of coaches adopting and using Knee Control. Adding even more levels of exercises and providing further examples for progression to make it fit both children and senior players, as suggested by the coaches, would probably also facilitate long-term use and make the transition from junior to senior levels better in terms of injury prevention. In a study in youth rugby the complexity of exercises was adapted to fit different age groups to make sure the exercises offered training stimulus for all teams ${ }^{33}$. Tailoring by offering more variation, progression and possibilities for individualisation has also been suggested in a study of professional male youth football players using the FIFA $11+^{34}$. The aim with the modifications was to improve player motivation, avoid boredom and to make the exercises fit the players' ${ }^{\prime}$ hysiological level ${ }^{32}$. Despite different contexts, populations and research designs the results of the present study are in line with these results. However, tailoring could also be negative because the injury preventive effect may be compromised, especially if changes are made at random. Knowledge about the effective core components of the IPEP is important before modifying programme content ${ }^{18}$. Since amateur coaches like those in the present study will probably not be as aware of the evidence base for IPEPs and as able to make sound modifications as the better educated coaches in professional football or rugby, clear instructions about how to tailor the programme are warranted. Whether tailoring really improves programme fidelity and player buy-in has, however, yet to be shown. 


\section{Methodological considerations}

With our semi-structured interview guide and open-ended questions, we had the opportunity to delve deeply into the experiences of the coaches. The inductive approach enabled us to analyse the results with a low level of preconceptions. Another strength was that all three researchers were involved in the analysis and discussed the categorization until consensus was reached, which strengthens the credibility of the study. The pilot interviews also strengthen the trustworthiness of the study. The negative case analysis that was carried out to make sure all interpretations were in line with the data at hand and moving from interviews to analysis back and forth also increased the trustworthiness.

Transferability of the study results must be judged by those who use them. This study was performed in Sweden, where coaching at this level is usually done on a non-profit basis in the coaches' spare time, which may differ from other countries. IPEP use may also differ between girls and boys, at elite level or among adults. In addition, all coaches knew about Knee Control beforehand and generalization to coaches not familiar with Knee Control or coaches familiar with another IPEP cannot be taken for granted. The results here are from the perspective of the coach. He or she may find player buy-in important, but how the players truly feel about Knee Control has not been studied. Additionally, it cannot be taken for granted that initiatives based on the coaches’ suggestions will improve player buy-in since coaches and players may perceive implementation of programmes differently ${ }^{29}$.

\section{Perspectives}

The results indicate that adoption and use of Knee Control was dependent on both coach motivation and external facilitators and barriers in combination with the characteristics of Knee Control. Coach motivation and prioritization of preventive training seemed to be crucial, but most coaches wished for extra support and interest from the FAs, clubs and 
players among others. To facilitate Knee Control use and increase player buy-in, the coaches had often modified the programme. Many coaches had come across Knee Control by chance, therefore dissemination efforts by the district FAs could probably be improved, which would also convey to coaches and players that prevention is a priority. This is an interesting find since the coaches in the present study worked in football districts where dissemination efforts had been considerable both during and after the original $\mathrm{RCT}^{4}$ compared to other districts where dissemination efforts had been more modest. The findings in the present study may guide the design and delivery of future IPEPs and also inform about improvements to Knee Control to increase long-term maintenance. For example, the app could be further developed to provide examples on how to tailor Knee Control for different target groups: children, adolescents and senior players, at amateur and elite level. In addition, efforts to implement Knee Control could be supplemented by practical workshops offering support to coaches and by increasing awareness of injuries and prevention among coaches, players and the wider community and by translating the app into other languages.

\section{Acknowledgements}

The authors would like to thank all participating coaches for their valuable participation in the study. This study received grants from the Swedish Research Council for Sport Science and from Region Östergötland, Sweden.

\section{References}

1. Frobell RB, Roos HP, Roos EM, Roemer FW, Ranstam J, Lohmander LS. Treatment for acute anterior cruciate ligament tear: five year outcome of randomised trial. BMJ 2013;346:f232. 
2. Olsen OE, Myklebust G, Engebretsen L, Holme I, Bahr R. Exercises to prevent lower limb injuries in youth sports: cluster randomised controlled trial. BMJ 2005;330:449.

3. Emery CA, Meeuwisse WH. The effectiveness of a neuromuscular prevention strategy to reduce injuries in youth soccer: a cluster-randomised controlled trial. Br J Sports Med 2010;44:555-562.

4. Waldén M, Atroshi I, Magnusson H, Wagner P, Hägglund M. Prevention of acute knee injuries in adolescent female football players: cluster randomised controlled trial. BMJ 2012;344:e3042.

5. Thorborg K, Krommes KK, Esteve E, Clausen MB, Bartels EM, Rathleff MS. Effect of specific exercise-based football injury prevention programmes on the overall injury rate in football: a systematic review and meta-analysis of the FIFA 11 and 11+ programmes. Br J Sports Med 2017;51:562-571.

6. Bizzini M, Dvorak J. FIFA 11+: an effective programme to prevent football injuries in various player groups worldwide-a narrative review. Br J Sports Med 2015;49:577-9.

7. Finch CF, Doyle TL, Dempsey AR, Elliott BC, Twomey DM, White PE, Diamantopoulou K, Young W, Lloyd DG. What do community football players think about different exercise-training programmes? Implications for the delivery of lower limb injury prevention programmes. Br J Sports Med 2014;48:702-707.

8. O'Brien J, Finch CF. A systematic review of core implementation components in team ball sport injury prevention trials. Inj Prev 2014;20:357-362.

9. Frank BS, Register-Mihalik J, Padua DA. High levels of coach intent to integrate a ACL injury prevention program into training does not translate to effective implementation. J Sci Med Sport 2015;18:400-406. 
10. Norcross MF, Johnson ST, Bovbjerg VE, Koester MC, Hoffman MA. Factors influencing high school coaches' adoption of injury prevention programs. J Sci Med Sport 2016;19:299-304.

11. Hägglund M, Atroshi I, Wagner P, Waldén M. Superior compliance with a neuromuscular training programme is associated with fewer ACL injuries and fewer acute knee injuries in female adolescent football players: secondary analysis of an RCT. Br J Sports Med 2013;47:974-979.

12. Myklebust G, Skjolberg A, Bahr R. ACL injury incidence in female handball 10 years after the Norwegian ACL prevention study: important lessons learned. Br J Sports Med 2013;47:476-479.

13. McKay CD, Verhagen E. 'Compliance' versus 'adherence' in sport injury prevention: why definition matters. Br J Sports Med 2016;50:382-383.

14. McKay CD, Steffen K, Romiti M, Finch CF, Emery CA. The effect of coach and player injury knowledge, attitudes and beliefs on adherence to the FIFA 11+ programme in female youth soccer. Br J Sports Med 2014;48:1281-1286.

15. Sugimoto D, Mattacola CG, Bush HM, Thomas SM, Foss KD, Myer GD, Hewett TE. Preventive neuromuscular training for young female athletes: comparison of coach and athlete compliance rates. J Athl Train 2017;52:58-64.

16. Saunders N, Otago L, Romiti M, Donaldson A, White P, Finch C. Coaches' perspectives on implementing an evidence-informed injury prevention programme in junior community netball. Br J Sports Med 2010;44:1128-1132.

17. Lindblom H, Waldén M, Carlfjord S, Hägglund M. Implementation of a neuromuscular training programme in female adolescent football: 3-year follow-up study after a randomised controlled trial. Br J Sports Med 2014;48:1425-1430. 
18. O'Brien J, Young W, Finch CF. The delivery of injury prevention exercise programmes in professional youth soccer: comparison to the FIFA 11. J Sci Med Sport 2017;20:2631.

19. Janz NK, Becker MH. The Health Belief Model: a decade later. Health Educ Q 1984;11:1-47.

20. Finch CF, White P, Twomey D, Ullah S. Implementing an exercise-training programme to prevent lower-limb injuries: considerations for the development of a randomised controlled trial intervention delivery plan. Br J Sports Med 2011;45:791-796.

21. O'Brien J, Finch CF. Injury prevention exercise programmes in professional youth soccer: understanding the perceptions of programme deliverers. BMJ Open Sport Exerc Med 2016;2:e000075.

22. Champion V, Skinner C. The health belief model. In: Glanz K, Rimer B, Viswanath K (eds.) Health behavior and health education - theory, research, and practice. 4th ed. San Francisco: Jossey-Bass; 2008.

23. Emery CA, Hagel B, Morrongiello BA. Injury prevention in child and adolescent sport: whose responsibility is it? Clin J Sport Med 2006;16:514-521.

24. Donaldson A, Poulos RG. Planning the diffusion of a neck-injury prevention programme among community rugby union coaches. Br J Sports Med 2014;48:151-159.

25. Donaldson A, Finch CF. Planning for implementation and translation: seek first to understand the end-users' perspectives. Br J Sports Med 2012;46:306-307.

26. Krippendorff K. Content analysis - an introduction to its methodology. London: Sage; 2013.

27. Patton. MQ. Qualitative research \& evaluation methods. London: Sage; 2002. 
28. Hsieh HF, Shannon SE. Three approaches to qualitative content analysis. Qual Health Res 2005;15:1277-1288.

29. McKay CD, Merrett CK, Emery CA. Predictors of FIFA 11+ implementation intention in female adolescent soccer: an application of the Health Action Process Approach (HAPA) model. Int J Environ Res Public Health 2016;13:657.

30. Bekker S, Clark AM. Bringing complexity to sports injury prevention research: from simplification to explanation. Br J Sports Med 2016;50:1489-1490.

31. O'Brien J, Donaldson A, Finch CF. It will take more than an existing exercise programme to prevent injury. Br J Sports Med 2016;50:264-265.

32. Joy EA, Taylor JR, Novak MA, Chen M, Fink BP, Porucznik CA. Factors influencing the implementation of anterior cruciate ligament injury prevention strategies by girls soccer coaches. J Strength Cond Res 2013;27:2263-9.

33. Hislop MD, Stokes KA, Williams S, McKay CD, England M, Kemp SPT, Trewartha G. The efficacy of a movement control exercise programme to reduce injuries in youth rugby: a cluster randomised controlled trial. BMC Open Sport Exerc Med 2016;2:e000043.

34. O’Brien J, Young W, Finch CF. The use and modification of injury prevention exercises by professional youth soccer teams. Scand J Med Sci Sports 2017;27:1337-1346. 
Table 1. Coach motivation for adoption and use of Knee Control: quotations according to sub-categories

\begin{tabular}{|c|c|}
\hline Sub-category & Quotations \\
\hline $\begin{array}{l}\text { Views on injuries } \\
\text { in football }\end{array}$ & $\begin{array}{l}\text { I think it's too high (the risk of injury), (...) you start to ponder about what you're doing when you } \\
\text { hear about the injuries that occur, so I think, I think it is a problem (C11) } \\
\text {...and then the sprains, you just (...) look at the game and run and then there's a pit in the grass and } \\
\text { you may suffer a sprain. I think there is nothing you can do to prevent it, it happens, it's part of the } \\
\text { game (C14) }\end{array}$ \\
\hline $\begin{array}{l}\text { Injury prevention } \\
\text { attitude }\end{array}$ & $\begin{array}{l}\text { I think the thing is that we, we are aware that girls easily injure their knees, and we have some girls } \\
\text { whose older sisters had severe injuries, which motivates us to keep doing this (use Knee Control) to } \\
\text { prevent injuries and to strengthen their bodies so that they won't have any issues in the future, that's } \\
\text { what drives us to use it (C10) } \\
\text { I could be more alert and take this more seriously if I was even more convinced that this (using } \\
\text { Knee Control) was important, then I probably would make more of an effort (C6) } \\
\text { but the coach responsible for today's training, he may not use it (Knee Control), he may think it's } \\
\text { great that we do it, but still prioritize other things (C12) } \\
\text { if I'm not there it won't be done (C14) }\end{array}$ \\
\hline $\begin{array}{l}\text { Beliefs about the } \\
\text { effects of Knee } \\
\text { Control }\end{array}$ & $\begin{array}{l}\text { If the football did benefit from it (Knee Control)?...That's hard for me to tell, to know. What would } \\
\text { have happened otherwise if we hadn't used it? That's always hard to tell, but yes, they performed } \\
\text { the exercises better and better and became stronger (C5) } \\
\text { Benefits will hopefully be seen later on, if it (Knee Control) reduces the knee injuries to that degree } \\
\text { (C1) }\end{array}$ \\
\hline
\end{tabular}

In the quotes, brackets () are used for additions by the authors and (...) is used when the quotes have been shortened. 
Table 2. External facilitators and barriers for adoption and use of Knee Control: quotations according to sub-categories

\begin{tabular}{|l|l|}
\hline Sub-category & Quotations \\
\hline $\begin{array}{l}\text { Social support } \\
\text { when adopting } \\
\text { and using Knee } \\
\text { Control }\end{array}$ & $\begin{array}{l}\text { sometimes you wish you would meet many more people saying that they use it. It happens, it } \\
\text { happens that I run into other coaches who do state that they use it, but that's very seldom (C9) } \\
\text { If they (the football associations) want this to be a tool for the future I think they should promote it a } \\
\text { little bit harder (C8) }\end{array}$ \\
\hline $\begin{array}{l}\text { Resources for use } \\
\text { of Knee Control }\end{array}$ & $\begin{array}{l}\text { if you for example have 75 minutes of training on artificial turf, then it's cold weather, you need to } \\
\text { programme, do some technique drills and some aerobic training and so on, there isn't enough time } \\
\text { for the Knee Control programme (C4) }\end{array}$ \\
$\begin{array}{l}\text { I have the app, so I do check quite carefully before training so that, so I can show it correctly and } \\
\text { rectify if they make an error, like placing a foot at the wrong angle or something like that (C19) }\end{array}$ \\
$\begin{array}{l}\text { my role is to be a football coach, I can't know everything (...) I handle the football and get help for } \\
\text { other things, there are so many capable people you can hire, you just have to find them and find } \\
\text { ways to arrange it financially, sure it costs a bit, but it's worth it (C5) }\end{array}$ \\
\hline $\begin{array}{l}\text { Player-related } \\
\text { factors } \\
\text { use of Knee } \\
\text { Control }\end{array}$ & $\begin{array}{l}\text { and the girls don't show any enthusiasm, they think it is really dull (C4) } \\
\text { quality. That's the case in all youth activities, there are kids who are giggly, immature, get bored of } \\
\text { listening, they don't understand the importance of doing exercises correctly, they are careless and } \\
\text { take shortcuts to finish the intended number of exercises early, they want to be first (C6) }\end{array}$ \\
\hline
\end{tabular}

In the quotes, brackets () are used for additions by the authors and (...) is used when the quotes have been shortened. 
Table 3. Programme characteristics influencing adoption and use of Knee Control: quotations according to sub-categories

\begin{tabular}{|l|l|}
\hline Sub-category & Quotations \\
\hline Knee Control fit & $\begin{array}{l}\text { they could have thought about how... could something similar be done with the ball, or doing it in } \\
\text { pairs, making the exercises more fun (C4) } \\
\text { the challenge sometimes is that you don't want to spend thirty minutes on this during training, but } \\
\text { then you have to find other solutions where you work with this, and that's what we are doing a lot } \\
\text { now, when we have breaks, while talking, they can do some exercises for example (C16) }\end{array}$ \\
& $\begin{array}{l}\text { well, I use parts of it, because I, I don't think all parts are good but I have selected what I consider } \\
\text { the most effective parts (C17) }\end{array}$ \\
\hline $\begin{array}{l}\text { Knee Control } \\
\text { feasibility }\end{array}$ & $\begin{array}{l}\text { It has been to and fro how much we have used it; after the summer we were very active and started } \\
\text { each training session with Knee Control exercises (...) and then there have been periods when we } \\
\text { thought that now we really ought to do this, but most of the time we only use a few selected } \\
\text { exercises (C7) }\end{array}$ \\
$\begin{array}{l}\text { to explain why you do an exercise and what it is meant for, that's really important, otherwise they } \\
\text { think they can do the number of repetitions as quickly as possible to get them over with, so it's } \\
\text { really important that they understand why (C5) }\end{array}$ \\
\hline
\end{tabular}

In the quotes, (...) is used when the quotes have been shortened. 
Supplementary information. Interview guide topics

Main question and probes

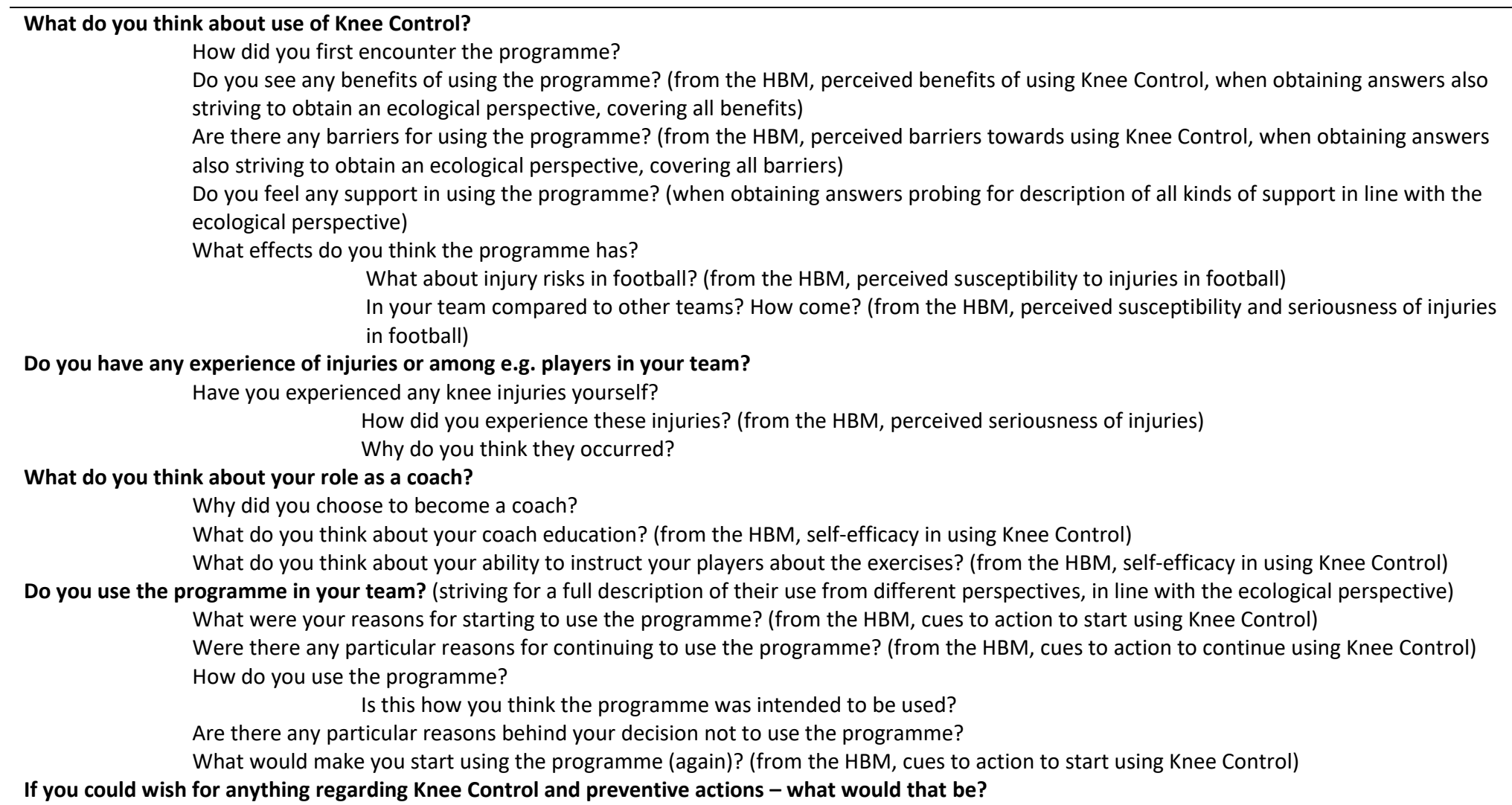

Abbreviations: HBM denotes the Health Belief Model 